\section{It's time to work together and stop duplicating conservation efforts ...}

Sir-Myers et al. ${ }^{1}$, in their new analysis of global biodiversity hotspots, recommend areas where conservation actions should be focused to minimize losses in the imminent extinction crisis. We strongly support initiatives to produce clear, efficient and practical goals for conservation to guide biodiversity planners and decision-makers in governments, agencies, conventions and non-governmental organizations (NGOs). However, as things stand there is only limited consensus on global conservation priorities at international level. We believe that the time is now right for scientists and practitioners to work together to develop a commonly adopted blueprint for action.

A key first step would be a structured debate to identify common goals; to pool data sets; and to agree on the contributions that non-equivalent measures of priority, such as diversity, endemism, threat, viability and ecological function should make. All this should lead to a powerful and cost-effective product. Most important, however, is that the sound analyses, breadth of expertise, and strength of consensus underpinning such an agenda would greatly increase the probability that decision-makers would adopt the resulting priority system, and take action to stem the loss of wild species and maintain critical ecosystem processes.

Currently there is much duplication of effort across organizations. Prioritization programmes with comparable goals to that of Myers and his collaborators at Conservation International are in progress at WWFUS $^{2}$, BirdLife International ${ }^{3}$, IUCN ${ }^{4}$, World Resources Institute $e^{5}$ and The Nature Conservancy ${ }^{6}$. All these are enormously costly, involving independent programmes to gather data, undertake analyses, and publish and advertise products. The result is considerable redundancy, and generation of competing rather than complementary priority sets ( sets of areas that result from systematic prioritization). We appreciate that organizations have to develop specific products to meet their own objectives. Nevertheless, we believe that leading NGOs must cooperate in data-gathering, analysis and prioritysetting if there is to be a widely supported strategy that the entire conservation community can work together to implement.

In our view, the analysis of Myers et al. ${ }^{1}$ highlights several other issues that must be addressed in reaching consensus. First, a coordinated programme must take account of the many recent advances in systematic priority-setting. The analysis by Myers et al. does not include new techniques allowing the identification of priority sets which, by paying explicit attention to patterns of between-site complementarity, greatly boost the efficient representation of all mapped species and not just endemics targeted in pre-selected sites ${ }^{7-10}$. These techniques also allow planners to justify the choice of particular areas, to determine the flexibility of site selection and to balance representation and conservation efficiency against a suite of socio-economic costs (such as land price, degree of land transformation, and human population density $)^{7,9-11}$.

Second, there remain several serious limitations to all current assessments of global priority. For instance, most conservation decisions take place at a finer geographical scale than that discussed by Myers et al. ${ }^{1}$. Hence new techniques, which allow analyses to move freely between different scales, are needed before global analyses can be translated into effective action on the ground. At these finer scales there are already some encouraging collaborations among academic researchers and NGOs (see the letter by Fonseca et al., below).

Equally pressing, priorities identified for one taxon may fail to reflect diversity in other groups ${ }^{12}$ - hence analyses should be developed from independent data sets from several taxa, ideally including invertebrates: the taxon that represents most terrestrial biodiversity. Biological priorities must also be integrated with socio-economic considerations, but current developments in this area are still at a rudimentary stage.

Last, conservation practitioners and academic researchers alike are concerned that systematic prioritization focuses on patterns of species and community distribution, yet largely fails to address the conservation of key ecological and evolutionary processes which maintain those patterns ${ }^{13}$. There is growing evidence that conserving the pattern will not by itself guarantee the conservation of these processes. Yet we currently lack robust measures for quantifying the extent to which different areas contribute to core processes, or for evaluating the overall performance of priority sets in terms of process maintenance. In consequence, although it is claimed that the hotspots approach is cost-effective ${ }^{1}$, problems concerning selection of areas, scale of analysis, socio-economic concerns and maintenance of key processes mean that areas of high conservation value may have been missed.

\section{G. M. Mace}

Institute of Zoology, Zoological Society of London, Regent's Park, London NW1 4RY, UK

A. Balmford University of Cambridge, UK

L. Boitani University of Rome, Italy

G. Cowlishaw Institute of Zoology, London, UK

A. P. Dobson Princeton University, USA

D. P. Faith Australian Museum, Sydney, Australia

K. J. Gaston University of Sheffield, UK

C. J. Humphries, R. I. Vane-Wright, P. H. Williams Natural History

Museum, London, UK
J. H. Lawton Imperial College, Ascot, UK

C. R. Margules CSIRO Tropical Forest Research Centre, Australia

R. M. May University of Oxford, UK

A. O. Nicholls CSIRO Wildlife and Ecology, Australia

H. P. Possingham University of Adelaide, Australia

C. Rahbek University of Copenhagen, Denmark

A. S. van Jaarsveld University of Pretoria, South Africa

1. Myers, N., Mittermeier, R. A., Mittermeier, C. G., da Fonseca, G. A. B. \& Kent, J. Nature 403, 853-858 (2000).

2. Olson, D. M. \& Dinerstein, E. Conserv. Biol. 12, 502-515 (1998).

3. Bibby, C. J. in Conservation Science and Action (ed. Sutherland, W. J.) 176-201 (Blackwell Science, Oxford, 1998).

4. WWF \& IUCN Centres of Plant Diversity: A Guide and Strategy for their Conservation 3 vols (IUCN Publications, Cambridge, 1994-97).

5. Ayensu, E. et al. Science 286, 685-686 (1999).

6. The Nature Conservancy Designing a Geography of Hope: Guidelines for Ecoregion-Based Conservation (The Nature Conservancy, Arlington, 1997).

7. Margules, C. R. \& Pressey, R. L. Nature 405, 243-253 (2000).

8. Pressey, R. L., Humphries, C. J., Margules, C. R., Vane-Wright, R. I. \& Williams, P. H. Trends Ecol. Evol. 8, 124-128 (1993).

9. Faith, D. P. et al. Forest Ecol. Mgmt 35, 251-260 (1996).

10. Williams, P. H. in Conservation in a Changing World (eds Mace, G. M., Balmford, A. \& Ginsberg, J.) 211-249 (Cambridge Univ. Press, Cambridge, 1998)

11. Rodrigues, A. S. L., Tratt, R., Wheeler, B. D. \& Gaston, K. J. Proc. R. Soc. Lond. B 266, 1453-1460 (1999).

12. van Jaarsveld, A. S. et al. Science 279, 2106-2108 (1998).

13. Balmford, A., Mace, G. M. \& Ginsberg, J. in Conservation in a Changing World (eds Mace, G.M., Balmford, A. \& Ginsberg, J.) 1-28 (Cambridge Univ. Press, Cambridge, 1998).

\section{.. following Africa's lead in setting priorities}

Sir - It is vital to try to conserve biological diversity, but to do this we must know where it is. New databases mapping African biodiversity now offer this information ${ }^{1-3}$.

Quantitative analyses ${ }^{4}$ of these data reveal geographical priorities for conservation broadly matching those generated at a global level by international conservation organizations $^{5-7}$ (Fig. 1, overleaf). Although this approximate overlap with coarse-scale priorities is encouraging, we now need to move tropical priority-setting to finer scales that will enable conservation action. We suggest here three strategies for meeting this challenge: improving data; enhancing collaborations; and working closely with local decision-makers.

The main constraint on quantitative conservation priority-setting ${ }^{8}$ is that sufficient data are not available at the fine scale required for conservation implementation. The only long-term solution is to collect new biological data, compile and disseminate point locality information, and conduct basic taxonomy. Such work is chronically under-funded, yet is essential for conservation planning'. In the short term, the problem can be reduced by deductive modelling. Environmental data such as elevation, vegetation, rainfall and temperature have been modelled to fine resolutions - for example, 1-km grids - for the whole continent (see http://edcftp. cr.usgs.gov). If we compile information on habitat preferences, we can 


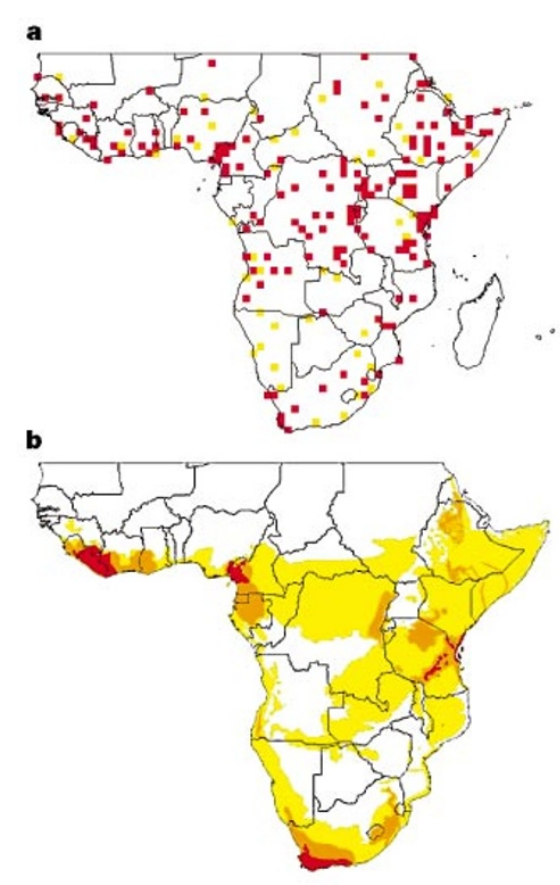

Figure 1 Conservation priorities for Sub-Saharan Africa. a, Quantitatively derived conservation priorities ${ }^{4}$ for $\sim 4,000$ species of bird, mammal, snake and amphibian, mapped on a $1^{\circ}$ grid. Coloured cells depict the top 200 areas from which $97.5 \%$ of species mapped have been recorded. Red squares are irreplaceable because they contain the entire known distribution of one or more species; orange cells are flexible areas for which alternatives (not mapped) are available. b, Conservation International's Hotspots5; the World Wildlife Fund US's Global 200 most biologically important ecoregions ${ }^{6}$; and BirdLife International's Endemic Bird Areas ${ }^{7}$. Red, orange and yellow show areas of intersection between three, two and one system(s), respectively.

predict fine-scale species distributions by overlaying environmental data onto speciesrange maps, to identify areas where all of a species' habitat requirements are fulfilled ${ }^{3}$. Another short cut is to base conservation priorities on well-known taxonomic group ${ }^{10}$. The problem with this is lack of knowledge of cross-taxon congruence ${ }^{11}-$ for example, conserving birds may not be enough to protect biodiversity as a whole.

Attempts to address the lack of data on African biodiversity must go hand-in-hand with improved collaboration at all levels see the letter from Mace et al. (page 393). Effective collaboration is urgently needed between the biological and social sciences, to incorporate human geography into the quantitative priority-setting process in the tropics ${ }^{12}$. The development of parallel priority-setting initiatives is another symptom of the lack of effective coordination to date. Furthermore, difficulties have arisen over data dissemination and public access to information. Such tensions between data providers (for example, museums) and users (such as non-governmental organizations) can be eased by considering mutually beneficial collaborations. For instance, conservation groups could increase their funding for the publication of biological data, and groups with mutual interests could collaborate on fund-raising to pay for data collection. Finally, much greater use should be made of existing collaborative networks ${ }^{13}$.

Effective translation of continental priorities into action depends fundamentally on consensus from local decision-makers. One way of forging this is through expertbased priority-setting workshops ${ }^{14}$ to assess key regional areas for conservation values in different taxonomic groups and to prioritize these areas across groups. From this synthesis, an integrated set of local priorities can be developed incorporating information on ecology, current and future threats, and landscape-level linkages. Essential components are a commitment to training, empowerment of local specialists, and repatriation of biodiversity information.

Such conservation-prioritization workshops have been held recently for the Upper Guinea region (December 1999) and for the Congo Basin (March 2000). The consensus forged by governmental, non-governmental and academic representatives from the countries in these regions has provided a solid base to translate priorities into action. We believe that our suggestions will considerably increase the chances of further progress while opportunities for effective conservation in Africa remain.

\section{Gustavo A. B. da Fonseca}

Conservation International Center for Applied Biodiversity Science, 2501 M Street NW, Washington DC 20037, USA, and Departamento de Zoologia, Universidade Federal de Minas Gerais, Avenida Antônio Carlos, 6627 Pampulha, Brazil Andrew Balmford University of Cambridge, UK

Colin Bibby BirdLife International, UK

Luigi Boitani, Fabio Corsi Istituto di Ecologia Applicata, Italy Thomas Brooks, Claude Gascon, Silvio Olivieri, Russell A. Mittermeier Conservation International Center for Applied Biodiversity Science, USA

Neil Burgess Wildlife Conservation Society of Tanzania Eric Dinerstein, David Olson World Wildlife Fund, USA Lee Hannah Conservation International, South Africa Jon Lovett University of York, UK David Moyer Wildlife Conservation Society, USA

Carsten Rahbek University of Copenhagen, Denmark Simon Stuart International Union for the Conservation of Nature and Natural Resources, Switzerland

Paul Williams Natural History Museum, UK

1. Burgess, N. et al. Species 30, 16-17 (1998).

2. Lovett, J. C. et al. Biodiv. Conserv. 9, 33-42 (2000).

3. Boitani, L. et al. AMD African Mammals Databank: A Databank for the Conservation and Management of the African Mammals (Istituto di Ecologia Applicata, Rome, 1999).

4. Williams, P. H. WORLDMAP 4.1. Priority Areas for Biodiversity (Natural History Museum, London, 1996).

5. Myers, N., Mittermeier, R. A., Mittermeier, C. G., da Fonseca, G. A. B. \& Kent, J. Nature 403, 853-858 (2000)

6. Olson, D. M. \& Dinerstein, E. Conserv. Biol. 12, 502-515 (1998).

7. Stattersfield, A. J. et al. Endemic Bird Areas of the World: Priorities for Biodiversity Conservation (BirdLife International, Cambridge, 1998).

8. Williams, P. H. in Conservation in a Changing World (eds Mace, G. M., Balmford, A. \& Ginsberg, J.) 211-249 (Cambridge Univ Press, Cambridge, 1998).

9. Balmford, A. \& Gaston, K. J. Nature 398, 204-205 (1998). 10. Bennun, L. A. \& Fishpool, L. D. C. Ostrich (in the press).
11. Howard, P. C. et al. Nature 394, 472-475 (1998).

12. Fjeldså, J. \& Rahbek, C. in Conservation in a Changing World (eds Mace, G. M., Balmford, A. \& Ginsberg, J.) 139-160 (Cambridge Univ. Press, Cambridge, 1998).

13. BCIS Framework for Information Sharing (Biodiversity Conservation Information System, Cambridge, 2000). 14. Olivieri, S. et al. A Participatory Approach to Biodiversity Conservation: the Regional Priority Setting Workshop (Conservation International, Washington DC, 1995).

\section{Community groups could show Unesco the way}

Sir - We approve of your recommendation that Unesco should focus more closely on its core goals (Nature 404, 109; 2000). And we wish to go further with some concrete suggestions. Within the UN system, Unesco is unique in having a double representation. Each member State has a permanent diplomatic delegation representing its government, and, in addition, a national commission representing the academic and scientific community and 'civil society' the grouping of all kinds of non-governmental organisations (NGOs) that exist to promote the interests of citizens.

The worldwide rise in influence of civil societies shows the way forward for Unesco. In all possible ways, Unesco should improve its relations with civil society organizations, and foster their development: closer cooperation with NGOs, universities and so on could actually lead to useful savings and increased efficiency.

Unesco should apply to its own functioning the principles of ethics and good governance. Its recurrent drifts into double standards (proclaiming lofty ideals while carrying out dubious internal practices) are no longer acceptable: Unesco should dedicate itself to promote a culture of evaluation.

Lastly, if we are serious about our social responsibilities, we scientists should see that science and technology remain firmly anchored inside Unesco.

Britain's return to Unesco in 1997 after leaving during the 1980s was a welcome move, but, for a proper implementation of the previous points, we do hope that the British National Commission for Unesco will be promptly reconstituted. From the French side, we eagerly look forward to fruitful discussions and stimulating debates with our British colleagues and partners. The pioneering contributions of Joseph Needham and Julian Huxley, at the birth of Unesco, have not been forgotten.

Our conviction is that the full restoration of this distinguished British tradition will be an important element in the renovation process of Unesco.

\section{Gérard Toulouse}

President of the Committee for Exact and Natural

Sciences (French National Commission for Unesco), Laboratoire de Physique de l'ENS, 24 rue Lhomond, 75231 Paris, France 